\title{
Is top-down therapy a more effective alternative to conventional step-up therapy for Crohn's disease?
}

\author{
Jonathan Jenkin Tsui ${ }^{a}$, Hien Q. Huynh ${ }^{\text {b }}$ \\ Edinburgh Medical School, University of Edinburgh, Edinburgh, UK; Stollery Children's Hospital, University of \\ Alberta, Edmonton, Alberta, Canada
}

\begin{abstract}
The management of Crohn's disease involves immunosuppressive protocols in a step-up approach that progresses through a therapeutic pyramid with several tiers of medication. Medications at the top are considered more potent but present greater risk. A new top-down approach to therapy inverts this procedure, using top-tier drugs for initial treatment. A critical appraisal of the current literature relating to top-down therapy was performed to evaluate its merit. A literature search was conducted on PubMed, Ovid, and PubMed Central to identify studies of the efficacy of top-down therapy. Papers were appraised critically using the Scottish Intercollegiate Guidelines Network score to evaluate current evidence for the use of top-down therapy. Nineteen studies were identified, including six randomized control trials, thirteen cohort studies, and two cost-benefit studies. Early combined therapy involving both biologics and immunomodulators was found to be effective at improving patient outcomes; however, early biologics alone were not shown to have a clear benefit over step-up therapy. Likewise, the early use of immunomodulators alone showed inconsistent results with respect to efficacy in terms of both remission and surgical outcomes. Evidence for application in pediatric populations was also inconclusive. The cost-benefit analyses found that top-down therapy merits investigation, as it proved to be economical given current data. Top-down therapy has the potential of being a viable alternative to step-up therapy, but further studies are needed to determine the most appropriate patients to receive this treatment.
\end{abstract}

Keywords Crohn's disease, medical treatment, top-down therapy, step-up therapy

Ann Gastroenterol 2018; 31 (3): 1-12

\section{Introduction}

Crohn's disease is a manifestation of an immune-mediated reaction to commensal microbes and potential dietary and environmental factors within the digestive tract associated with genetically susceptible individuals [1]. While Crohn's disease is considered a chronic disease, patients often go into periods known as remission when symptoms are under control. The return of symptoms is often characterized by

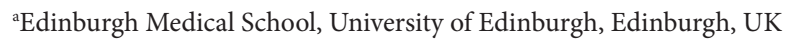
(Jonathan Jenkin Tsui); 'Department of Pediatrics, Stollery Children's Hospital, University of Alberta, Edmonton, Alberta, Canada (Hien Q. Huynh)

\section{Conflict of Interest: None}

Correspondence to: Jonathan Jenkin Tsui, BSc, Edinburgh Medical School, University of Edinburgh, Teviot Place, Edinburgh EH8 9AG, UK, e-mail: jenkin.tsui579@gmail.com

Received 25 September 2017; accepted 2 February 2018; published online 28 March 2018

DOI: https://doi.org/10.20524/aog.2018.0253 severe clusters of complications known as flare-ups [2]. Currently, there is no cure for Crohn's disease and surgery is often performed when the progression of the disease causes extensive damage. Furthermore, patients who undergo this intervention have a high chance of relapse even after surgical management [3].

There are several outcomes aimed for with the treatment of Crohn's disease. Remission, commonly graded by the Crohn's disease activity index (CDAI) or Harvey Bradshaw index (HBI) scoring system, is one such outcome. Other outcomes include the avoidance of surgery, endoscopic mucosal remission, and reduction of long-term bowel damage. Step-up therapy was previously the accepted treatment protocol for Crohn's disease [4-7]. As shown in Fig. 1, this protocol involves the use of relatively safe medications, but with lesser efficacy, before incrementally increasing to medications of greater efficacy but potentially greater risk. However, in recent years there has been a shift towards the adoption of a combined or top-down therapy.

The alternative drug therapy protocol known as "top-down" therapy (Fig. 1) has been contemplated in guidelines. It involves the use of more potent drugs early in patient care [8]. Biologics 


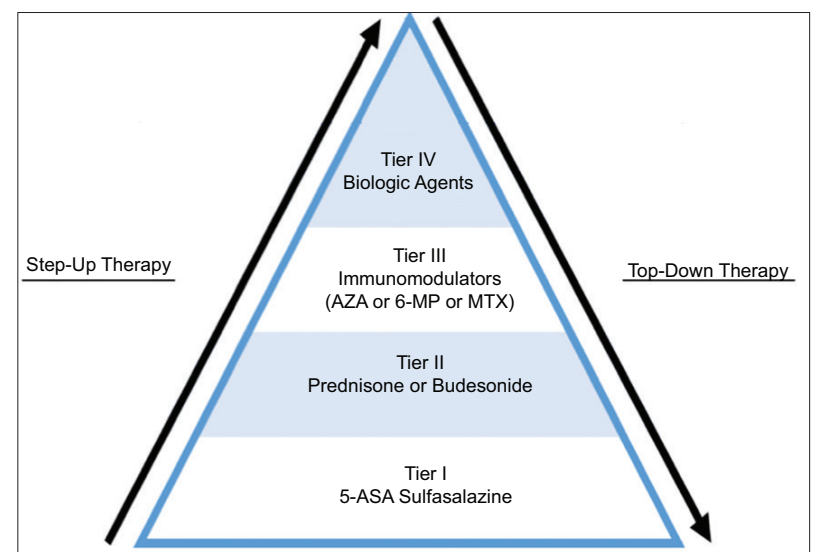

Figure 1 Therapeutic pyramid (Figure adapted from diagram created by Aloi et al [50])

IFX, infliximab; ADA, adalimumab; CP, certolizumab pegol; AZA, azathioprine; 6-MP, 6-mercaptopurine; 5-ASA, 5-aminosalicylic acid

and immunosuppressants are administered immediately after the diagnosis of Crohn's disease [9].

The exact protocol of top-down therapy is not universally defined because of the variety of drugs used. Initially, many health practices moved away from stepping up to immunomodulators after an initial trial of corticosteroid and 5-aminosalicylic acid to a top-down approach involving the early initiation of immunomodulators. However, in the past 20 years biologic drugs became available for clinicians, as clinical trials showed their efficacy in the treatment of Crohn's disease $[10,11]$. These mainly include infliximab (ACCENT 1 trial [12]), adalimumab (CLASSIC I [13] and GAIN trial [14]), and certolizumab pegol (PRECISE 1 [14] and PRECISE 2 [15]). In addition, vedolizumab (GEMINI [15]) and ustekinumab (UNITI [16]) trials have also been conducted. Therefore, the definition of top-down has shifted from the early use of immunomodulators to the early use of biologics. Consequently, top-down therapy can be categorized into three distinct treatment protocol designs: 1) early use of biologics, such as infliximab, adalimumab, and certolizumab pegol; 2) early use of immunomodulators, such as azathioprine, 6-mercaptopurine, and methotrexate; and 3) top-down/ early combined (early use of both immunomodulators and biologics). Those protocols are in contrast with traditional "step-up" approaches, which start with topically acting oral steroids, followed by systemic steroids, and by immunomodulators and biologic agents in steroid-dependent or resistant patients.

Nevertheless, there is controversy in the medical community over the safety, efficacy, and cost involved with top-down therapy. Thus, before this new protocol is applied in hospitals, data from recent studies should be considered to determine the benefits and risks of this proposed treatment. Additionally, the high cost and the lack of reimbursement for the medications in most countries are important considerations in the choice between top-down strategies and step-up therapy. In view of these concerns, a critical appraisal of top-down therapy is desirable. In this review, a description and report of the findings from a critical appraisal of the current literature relating to top- down therapy and its merits for application in the clinical field will be addressed.

\section{Materials and methods}

\section{Search strategy and criteria}

A literature search was carried out to find studies relevant to the topic. Studies were screened using online databases for publications up to the date of 31 July 2017. PubMed and Ovid were used to collect clinical trials and studies. PubMed Central (PMC) was also searched for potentially missed studies.

To find relevant articles for this review, inclusion criteria were set, and several relevant search phrases were used. All three databases (PubMed, Ovid, and PMC) were queried using the following search phrases.

- Crohn's disease top-down

- Crohn's disease step-up

- Crohn's disease early therapy

- Crohn's disease early treatment

- Crohn's disease early immunomodulators

- Crohn's disease early biologics

- Crohn's disease early anti-tumor necrosis factor (TNF)

The screening process was broken down into several steps and was completed by the primary investigator. Search results were first subjected to screening by title alone. The paper was excluded if the title lacked any of the key phrase or words (i.e. Crohn's disease, top-down, step-up, therapy, treatment, immunomodulators, biologics, anti-TNF), as were any duplicates. Papers included after this step were assessed by abstract content to confirm that the paper reported a clinical trial. Following this, the papers were assessed to eliminate incomplete studies or data. Finally, the papers were assessed through appraisal of the entire article. Crohn's disease was the focus of the investigation and hence any article referring to ulcerative colitis was removed. Articles focusing on postoperative, hepatic, genetic, diagnostic, and animal studies were excluded. Non-English language studies were not included. Duplicate findings were removed manually.

\section{Literature appraisal}

Complete articles were collected and were further narrowed down using the Critical Appraisal Skills Programme (CASP) tool to ensure a high level of quality within the final studies. Biases in the papers were identified using a chart to identify different types of bias (see Appendix). An evidence score was assigned using the Scottish Intercollegiate Guidelines Network framework (SIGN; www.sign.ac.uk) (Table 1). Results were collected, and the data were used as the basis of a discussion to answer the questions stated in the objectives. 
Table 1 Scottish intercollegiate guidelines network framework (SIGN) score

\begin{tabular}{ll} 
Classification & Description \\
\hline $1++$ & High quality meta-analyses, systematic reviews of RCTs, or RCTs with a very low risk of bias \\
$1+$ & Well-conducted meta-analyses, systematic reviews, or RCTs with a low risk of bias \\
$1-$ & Meta-analyses, systematic reviews, or RCTs with a high risk of bias \\
$2++$ & $\begin{array}{l}\text { High quality systematic reviews of case control or cohort or studies } \\
\text { High quality case control or cohort studies with a very low risk of confounding or bias and a high probability that the } \\
\text { relationship is causal }\end{array}$ \\
$2+$ & $\begin{array}{l}\text { Well-conducted case control or cohort studies with a low risk of confounding or bias and a moderate probability that } \\
\text { the relationship is causal }\end{array}$ \\
$2-$ & $\begin{array}{l}\text { Case control or cohort studies with a high risk of confounding or bias and a significant risk that the relationship is not } \\
\text { causal }\end{array}$ \\
\hline 3 & $\begin{array}{l}\text { Non-analytic studies, e.g. case reports, case series } \\
\text { Expert opinion }\end{array}$ \\
\hline
\end{tabular}

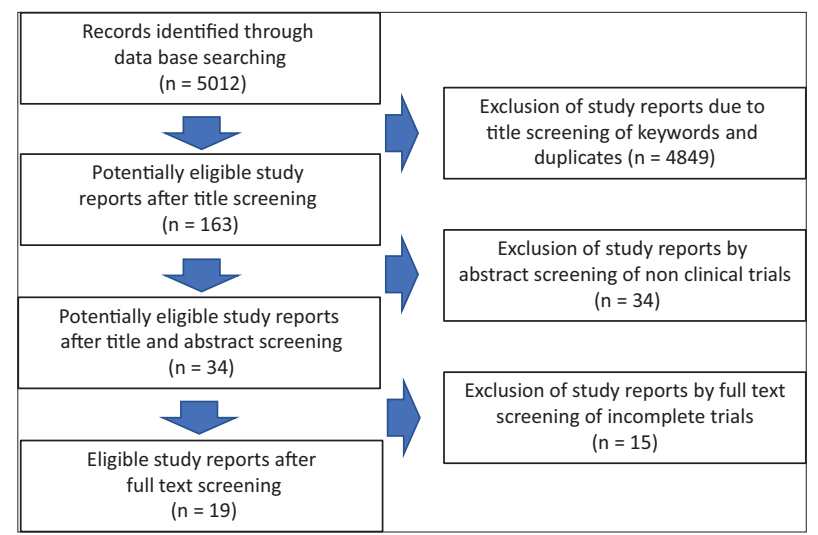

Figure 2 Flowchart of review process

\section{Results}

\section{Review process}

After the removal of duplicates, 163 papers were found to be of interest by title. Of these, 34 articles were found to be of interest by abstract and were then included for analysis. Fifteen studies were subsequently excluded, leaving 19 articles for analysis. The search process is summarized in Fig. 2.

\section{Main characteristics}

The search found 19 different clinical trials on top-down therapy. General characteristics of the included studies are summarized in Tables 2 and 3.

\section{Study types and quality}

Of the 19 clinical studies, 6 were randomized control trials (RCTs) [17-22]. The other 13 were cohort studies [22-33], of which 12 were retrospective and one was prospective.
In general, the SIGN level of evidence is considered higher with cohort studies and RCTs; therefore, high-quality studies were sought out. The studies chosen were subjected to the CASP tool for appraisal (see Appendix for link to CASP website). The SIGN level and a bias checklist were used to determine the score of the papers. Overall, the six RCTs were of high quality [17-22]. Eleven of the cohort studies [23-29,32-34] were considered of high quality (score of $2+$ and above) while two others [30,31] were considered of low quality. The variability and the difficulty of managing large patient groups was the source of many the faults in the RCTs. For the cohort studies, the fact that they were retrospective added a level of bias. The appraisal SIGN score and paper conclusions are provided in Table 4 . The results were also categorized according to location, patient population and medication and timing of top-down therapy with respect to their outcomes (primary endpoint, CDAI or HBI remission and need for surgery).

\section{Location}

There was a difference in the number of centers involved in studies. Some studies collected data from single centers while others included multiple centers. Single centers provide the advantage of having greater standardization in treatment protocol but may have limited patient capture.

\section{Patient population}

Regarding patient age, there were five pediatric studies [21,30-33,35], while the remainder involved adults $[17,19,20,22-25,27-29,34,36]$. "Pediatric" was defined as less than 18 years old, except for one paper [17] where patients were classified as adults at the age of 16 .

\section{Medication and timing of top-down therapy}

Top-down therapy has varying definitions. The two varying parts of the protocol are the definitions of medications used 
4 J. J. Tsui and H. Q. Huynh

Table 2 Results from adult studies

\begin{tabular}{|c|c|c|c|c|c|c|c|c|c|c|}
\hline Authors & $\begin{array}{l}\text { Trial } \\
\text { length }\end{array}$ & $\begin{array}{l}\text { No. of } \\
\text { centers }\end{array}$ & Region & Outcome assessment & Comparison & IM & $\mathrm{BIO}$ & Timing & $\begin{array}{l}\text { No. of } \\
\text { patients }\end{array}$ & Cohorts \\
\hline $\begin{array}{l}\text { D'Haens } \\
\text { et al [17] }\end{array}$ & 24 months & 18 & Europe & Remission $=\mathrm{CDAI} \leq 150$ & $\begin{array}{l}\text { Combined } \\
\text { vs. Step-up }\end{array}$ & $\begin{array}{l}\text { 6-MP, } \\
\mathrm{AZA}\end{array}$ & IFX & At week 0 & 133 & $\begin{array}{l}\text { SU: } 66 \\
\text { TD: } 67\end{array}$ \\
\hline Fan et al [18] & 24 months & 1 & East Asia & Remission $=\mathrm{CDAI} \leq 150$ & $\begin{array}{l}\text { Combined } \\
\text { vs. Step-up }\end{array}$ & AZA & IFX & At week 0 & 77 & $\begin{array}{l}\text { SU: } 39 \\
\text { TD: } 38\end{array}$ \\
\hline $\begin{array}{l}\text { Khanna } \\
\text { et al [22] }\end{array}$ & $\begin{array}{l}3 \text { years } 8 \\
\text { months }\end{array}$ & 41 & $\begin{array}{l}\text { North } \\
\text { America } \\
+ \text { Europe }\end{array}$ & $\mathrm{HBI} \leq 4$ & $\begin{array}{l}\text { Combined } \\
\text { vs. Step up }\end{array}$ & & & $\begin{array}{l}4 \text { weeks or } 12 \\
\text { weeks }\end{array}$ & 1982 & $\begin{array}{l}\text { SU: } 1084 \\
\text { TD: } 898\end{array}$ \\
\hline $\begin{array}{l}\text { Ghazi } \\
\text { et al [23] }\end{array}$ & 12 months & 1 & Europe & Remission $=\mathrm{HBI} \leq 5$ & $\begin{array}{l}\text { Bio vs. } \\
\text { Step-up }\end{array}$ & & $\begin{array}{l}\text { IFX, } \\
\text { ADA, } \\
\text { CP }\end{array}$ & At week 0 & 93 & $\begin{array}{l}\text { SU: } 39 \\
\text { TD: } 54\end{array}$ \\
\hline $\begin{array}{l}\text { Kim } \\
\text { et al [24] }\end{array}$ & 20 years & 15 & East Asia & Rates of operation & $\begin{array}{l}\text { Bio vs. } \\
\text { Step-up }\end{array}$ & & IFX & $\begin{array}{l}\text { Within } 1 \text { year of } \\
\text { diagnosis }\end{array}$ & 721 & $\begin{array}{l}\text { SU: } 278 \\
\text { TD: } 443\end{array}$ \\
\hline $\begin{array}{l}\mathrm{Ma} \\
\text { et al [34] }\end{array}$ & 12 years & 1 & $\begin{array}{l}\text { North } \\
\text { America }\end{array}$ & Rates of operation & $\begin{array}{l}\text { Bio vs. } \\
\text { Step-Up }\end{array}$ & & $\begin{array}{l}\text { IFX, } \\
\text { ADA }\end{array}$ & Within 2 years & 190 & $\begin{array}{l}\text { SU: } 137 \\
\text { TD: } 53\end{array}$ \\
\hline $\begin{array}{l}\text { Panés } \\
\text { et al [19] }\end{array}$ & 18 months & 31 & Europe & Remission $=\mathrm{CDAI} \leq 150$ & $\begin{array}{l}\text { IM vs. } \\
\text { step-up }\end{array}$ & AZA & & At week 0 & 131 & $\begin{array}{l}\text { SU: } 63 \\
\text { TD: } 68\end{array}$ \\
\hline $\begin{array}{l}\text { Cosnes } \\
\text { et al }[20]\end{array}$ & 36 months & 24 & Europe & Remission $=$ CDAI $\leq 150$ & $\begin{array}{l}\text { IM vs. } \\
\text { step-up }\end{array}$ & AZA & & $\begin{array}{l}\text { Within } 6 \text { months } \\
\text { of diagnosis }\end{array}$ & 147 & $\begin{array}{l}\text { SU: } 75 \\
\text { TD: } 72\end{array}$ \\
\hline $\begin{array}{l}\text { Kwak } \\
\text { et al [25] }\end{array}$ & 12 months & 1 & East Asia & Remission $=\mathrm{CDAI} \leq 150$ & $\begin{array}{l}\text { IM vs. } \\
\text { step-up }\end{array}$ & AZA & & $\begin{array}{l}\text { Within } 6 \text { months } \\
\text { of diagnosis }\end{array}$ & 168 & $\begin{array}{l}\text { SU: } 66 \\
\text { TD: } 102\end{array}$ \\
\hline $\begin{array}{l}\text { Chatu } \\
\text { et al [26] }\end{array}$ & 21 years & N/A & Europe & Rates of operation & $\begin{array}{l}\text { IM vs. } \\
\text { step-up }\end{array}$ & AZA & & $\begin{array}{l}\text { Within } 1 \text { year of } \\
\text { diagnosis }\end{array}$ & 879 & $\begin{array}{l}\text { SU: N/A } \\
\text { TD: N/A }\end{array}$ \\
\hline $\begin{array}{l}\text { Ramadas } \\
\text { et al [27] }\end{array}$ & 17 years & 1 & Europe & Rates of operation & $\begin{array}{l}\text { IM vs. } \\
\text { step-up }\end{array}$ & AZA & & $\begin{array}{l}\text { Within } 1 \text { year of } \\
\text { diagnosis }\end{array}$ & 341 & $\begin{array}{l}\text { SU: } 212 \\
\text { TD: } 129\end{array}$ \\
\hline $\begin{array}{l}\text { Kariyawasam } \\
\text { et al [28] }\end{array}$ & 39 years & 1 & Australia & Rates of operation & $\begin{array}{l}\text { IM vs. } \\
\text { step-up }\end{array}$ & $\begin{array}{l}\text { AZA, } \\
\text { MTX }\end{array}$ & & $\begin{array}{l}\text { Within } 3 \text { years of } \\
\text { diagnosis }\end{array}$ & 1035 & $\begin{array}{l}\text { SU: } 846 \\
\text { TD: } 189\end{array}$ \\
\hline $\begin{array}{l}\text { Lakatos } \\
\text { et al [29] }\end{array}$ & 32 years & 7 & Europe & Rates of operation & $\begin{array}{l}\text { IM vs. } \\
\text { step-up }\end{array}$ & AZA & & $\begin{array}{l}\text { Within } 1.5 \text { years } \\
\text { of diagnosis, } \\
\text { Within } 3.0 \text { years } \\
\text { of diagnosis } \dagger\end{array}$ & 501 & $\begin{array}{l}\text { SU: } 378 \\
\text { TD: } 123\end{array}$ \\
\hline
\end{tabular}

${ }^{*}$ Medication was given after maximum of 6 weeks prednisone induction, $\uparrow$ very early $=$ within 1.5 years of diagnosis, early $=$ within 3.0 years of diagnosis

IM, immunomodulator; BIO, biologics; 6-MP, 6-mercaptopurine; AZA, azathioprine; MTX, methotrexate; IFX, infliximab; ADA, adalimumab; CP, certolizumab pegol

Table 3 Results from pediatric studies

\begin{tabular}{|c|c|c|c|c|c|c|c|c|c|c|}
\hline Study & $\begin{array}{l}\text { Trial } \\
\text { length }\end{array}$ & $\begin{array}{l}\text { No. of } \\
\text { centers }\end{array}$ & Region & Outcome assessment & Comparison & IM & $\mathrm{BIO}$ & Timing & $\begin{array}{c}\text { No. of } \\
\text { patients }\end{array}$ & Cohorts \\
\hline $\begin{array}{l}\text { Lee } \\
\text { et al [31] }\end{array}$ & 24 months & 1 & East Asia & Remission $=$ PCDAI $\leq 10$ & $\begin{array}{l}\text { Combined vs } \\
\text { Bio vs Step-up }\end{array}$ & & IFX & At week 0 & 36 & $\begin{array}{l}\text { SU: } 10 \\
\text { TD (AZA): } 13 \\
\text { TD (IFX + AZA): } 13\end{array}$ \\
\hline $\begin{array}{l}\text { Walters } \\
\text { et al [35] }\end{array}$ & 12 months & 1 & $\begin{array}{l}\text { North } \\
\text { America }\end{array}$ & Remission $=$ PCDAI $\leq 10$ & $\begin{array}{l}\text { Bio vs IM vs } \\
\text { Step-up }\end{array}$ & $\begin{array}{l}\text { 6-MP, } \\
\text { MTX }\end{array}$ & $\begin{array}{l}\text { IFX, } \\
\text { ADA }\end{array}$ & $\begin{array}{l}\text { Within } 3 \text { months } \\
\text { of diagnosis }\end{array}$ & 552 & $\begin{array}{l}\text { SU: } 236 \\
\text { TD (BIO mono): } 68 \\
\text { TD (IM mono): } 248\end{array}$ \\
\hline $\begin{array}{l}\text { Lee } \\
\text { et al [30] }\end{array}$ & 36 months & 1 & East Asia & Remission $=\mathrm{PCDAI} \leq 10$ & Bio vs Step-up & & IFX & At week 0 & 28 & $\begin{array}{l}\text { SU: } 10 \\
\text { TD: } 18\end{array}$ \\
\hline $\begin{array}{l}\text { Olbjørn } \\
\text { et al [32] }\end{array}$ & 12 months & 28 & Europe & Remission $=$ PCDAI $\leq 10$ & Bio vs Step-up & & IFX & At week 0 & 36 & $\begin{array}{l}\text { SU: } 18 \\
\text { TD: } 18\end{array}$ \\
\hline $\begin{array}{l}\text { Markowitz } \\
\text { et al [21] }\end{array}$ & 18 months & 18 & $\begin{array}{l}\text { North } \\
\text { America }\end{array}$ & Remission $=\mathrm{HBI} \leq 3$ & IM vs Step-up & 6-MP & & $\begin{array}{l}\text { Within } 8 \text { weeks } \\
\text { of diagnosis }\end{array}$ & 501 & $\begin{array}{l}\text { SU: } 378 \\
\text { TD: } 123\end{array}$ \\
\hline $\begin{array}{l}\text { Punati } \\
\text { et al [33] }\end{array}$ & 12 months & 18 & $\begin{array}{l}\text { North } \\
\text { America }\end{array}$ & Remission $=$ PCDAI $\leq 10$ & IM vs Step-up & $\begin{array}{l}\text { 6-MP, } \\
\text { AZA }\end{array}$ & & $\begin{array}{l}\text { Within } 3 \text { months } \\
\text { of diagnosis }\end{array}$ & 247 & $\begin{array}{l}\text { SU: } 49 \\
\text { TD: } 150\end{array}$ \\
\hline
\end{tabular}


Table 4 Summary of study appraisals

\begin{tabular}{|c|c|c|c|c|c|}
\hline Authors & Conclusion on top-down therapy & $\mathrm{P} / \mathrm{A}$ & Type & SS & SIGN \\
\hline D'Haens et al [17] & $\begin{array}{l}\text { Combined early immunosuppression is more effective than conventional } \\
\text { therapy at inducing remission. Combined early immunosuppression } \\
\text { decreases need for corticosteroids }\end{array}$ & A & RCT & 133 & $1+$ \\
\hline Fan et al [18] & $\begin{array}{l}\text { Combined early immunosuppression is more effective than conventional } \\
\text { therapy at inducing remission and mucosal healing. Combined early } \\
\text { immunosuppression decreases need for steroids }\end{array}$ & A & RCT & 77 & $1+$ \\
\hline Khanna et al [22] & $\begin{array}{l}\text { Early combined immunosuppression was not more effective than } \\
\text { conventional step-up management of CD symptoms. Early combined } \\
\text { immunosuppression was not associated with an increased risk of serious } \\
\text { drug related adverse events }\end{array}$ & A & RCT & 1982 & $1++$ \\
\hline Ghazi et al [23] & $\begin{array}{l}\text { Early biologic therapy is no more effective at promoting remission than } \\
\text { conventional therapy. Early biologic therapy was associated with more } \\
\text { hospitalizations }\end{array}$ & A & $\mathrm{RC}$ & 93 & $2+$ \\
\hline Kim et al [24] & $\begin{array}{l}\text { Early infliximab therapy is not associated with a reduction in the need for } \\
\text { surgery }\end{array}$ & A & $\mathrm{RC}$ & 721 & $2++$ \\
\hline Ma et al [34] & $\begin{array}{l}\text { Early infliximab or adalimumab is associated with a reduction in the need } \\
\text { for surgery }\end{array}$ & A & $\mathrm{RC}$ & 190 & $2++$ \\
\hline Panés et al [19] & $\begin{array}{l}\text { Early immunomodulatory therapy is no more effective than conventional } \\
\text { therapy at inducing remission and reducing corticosteroid use }\end{array}$ & A & RCT & 131 & $1++$ \\
\hline Cosnes et al [20] & $\begin{array}{l}\text { Early immunomodulatory therapy is no more effective than conventional } \\
\text { therapy at increasing time in remission }\end{array}$ & A & RCT & 147 & $1++$ \\
\hline Kwak et al [25] & $\begin{array}{l}\text { Early immunomodulatory therapy is more effective than conventional } \\
\text { therapy at inducing remission. Early immunomodulatory therapy is not } \\
\text { more effective at preventing relapse }\end{array}$ & A & $\mathrm{RC}$ & 168 & $2+$ \\
\hline Chatu et al [26] & $\begin{array}{l}\text { Early immunomodulatory therapy is not associated with a reduction in the } \\
\text { need for surgery }\end{array}$ & A & $\mathrm{RC}$ & 879 & $2+$ \\
\hline Ramadas et al [27] & $\begin{array}{l}\text { Early and increased immunomodulatory therapy is associated with } \\
\text { reduction in the need for surgery }\end{array}$ & A & $\mathrm{RC}$ & 341 & $2+$ \\
\hline Kariyawasam et al [28] & $\begin{array}{l}\text { Early immunomodulatory therapy is associated with reduction in the need } \\
\text { for surgery }\end{array}$ & A & $\mathrm{RC}$ & 1035 & $2+$ \\
\hline Lakatos et al [29] & $\begin{array}{l}\text { Early and increased immunomodulatory therapy is associated with } \\
\text { reduction in the need for surgery }\end{array}$ & A & $\mathrm{RC}$ & 501 & $2+$ \\
\hline Lee et al [31] & $\begin{array}{l}\text { Early infliximab therapy is more effective than early immunomodulatory } \\
\text { therapy and conventional therapy at reducing relapse. Early } \\
\text { immunomodulatory therapy is more effective than conventional therapy at } \\
\text { reducing relapse }\end{array}$ & $\mathrm{P}$ & $\mathrm{RC}$ & 36 & $2-$ \\
\hline Walters et al [35] & $\begin{array}{l}\text { Early biologic therapy is more effective than conventional therapy } \\
\text { and early immunomodulatory therapy at inducing remission. Early } \\
\text { immunomodulatory therapy is not more effective than conventional } \\
\text { therapy at inducing remission }\end{array}$ & $\mathrm{P}$ & $\mathrm{RC}$ & 552 & $2++$ \\
\hline Lee et al [30] & $\begin{array}{l}\text { Early infliximab therapy is more effective than conventional therapy at } \\
\text { reducing relapse }\end{array}$ & $\mathrm{P}$ & $\mathrm{RC}$ & 28 & $2-$ \\
\hline Olbjørn et al [32] & $\begin{array}{l}\text { Early infliximab therapy is more effective than conventional therapy at } \\
\text { inducing remission }\end{array}$ & $\mathrm{P}$ & $\mathrm{PC}$ & 36 & $2+$ \\
\hline Markowitz et al [21] & $\begin{array}{l}\text { Early 6-MP is more effective than conventional therapy at inducing } \\
\text { and maintaining remission. Early use of 6-MP decreases need for } \\
\text { corticosteroids }\end{array}$ & $\mathrm{P}$ & RCT & 501 & $1++$ \\
\hline Punati et al [33] & $\begin{array}{l}\text { Early immunomodulatory therapy is no different than conventional } \\
\text { therapy at promoting remission. Early immunomodulatory therapy } \\
\text { is more effective at decreasing corticosteroid use and reducing } \\
\text { hospitalizations }\end{array}$ & $\mathrm{P}$ & $\mathrm{RC}$ & 247 & $2++$ \\
\hline
\end{tabular}

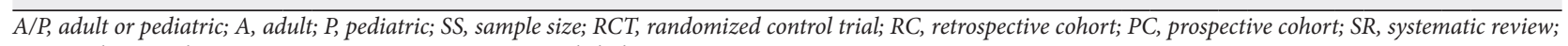
MS, Markov simulation; 6-MP, 6-mercaptopurine; $C D$, Crohn's disease 
and the timing of treatment. Top-down therapies varied between the use of immunomodulators and biologics as the frontline treatment. Immunomodulators used in the studies were azathioprine, 6-mercaptopurine, and methotrexate. The biologic treatments were infliximab, adalimumab, and certolizumab pegol.

The adult studies showed variation in the medications used. Three studies $[17,18,22]$ looked directly into early combined therapy versus step-up therapy. Three studies [23,24,34] investigated early biologic therapy versus step-up therapy. Seven studies [19,20,25-29] evaluated immunomodulatory monotherapy versus step-up therapy.

Likewise, the pediatric studies differed in the therapy used. One study [35] looked at both immunomodulators and biologic monotherapy through the use of three cohorts. Another study [35] compared early biologic, early immunomodulatory, and step-up therapy in three cohorts. Two studies $[30,32]$ looked into early biologic versus step-up and another two $[21,33]$ looked into early immunomodulatory versus step-up therapy.

Treatment timing also varied in the timing of the first dose of top-down medication in the trial studies. Seven studies [17-19,23,30-32] defined the start of top-down therapy at week 0 . Four defined it within three months and two within six months $[20,21,33,35]$. The remaining four studies [22,26-29,34] considered patients with initiation ranging from within a year to three years. This included one study that assigned different categories for within one and a half years and three years [29].

\section{Primary endpoints}

Primary endpoints varied across the studies. Remission is one of the final endpoint goals for the treatment of Crohn's disease; however, the definition of remission varied depending on each study. Five pediatric cases [21,30-33] were assessed using the pediatric Crohn's disease activity index (PCDAI). One was assessed using HBI score [21]. Remission was determined when the score was $\leq 10$. Five of the adult studies [17-20,25] used the CDAI score. Remission was determined when the score was $\leq 150$. Two papers $[22,23]$ used the HBI to score disease activity. The other main endpoint was the probability of surgery, used by the remaining five studies [24,26-29,34].

\section{Inducing remission}

Among the seven adult studies [17-20,22,23,25] that evaluated the use of top-down therapy in relation to remission, differing results were found. Two studies $[17,18]$ showed an overall positive result from the use of top-down therapy, and four $[19,20,22,23,25]$ showed an overall negative result. With the pediatric cases, four studies [21,30-32] showed an overall positive result from the use of top-down therapy and one study showed an overall negative result [33]. The last study [33] showed a tiered result in which early biologic therapy was superior to early immunomodulators, superior to step-up therapy.

\section{Reducing surgery}

The results from the studies that used operation rates as a final endpoint also showed differing conclusions. Results from four of the studies $[27-29,34]$ found that top-down therapy was associated with a decrease in rates for surgery. The remaining two studies $[24,26]$ did not associate top-down therapy with better surgical outcomes.

\section{Discussion}

This is the first critical review of the available literature for evidence of the efficacy of "top-down" treatment of Crohn's disease. In spite of finding several high-quality studies, as defined by the SIGN criteria, no clear overall conclusive conclusion can be drawn because of the difficulty in consistently comparing and analyzing the studies. Nevertheless, a subanalysis of the evidence regarding top-down therapy in the pediatric population was also performed to evaluate its clinical implications.

Top-down therapy has been proposed as an alternative, since studies showed that immunosuppression therapy was effective in the management of Crohn's disease [12,15,37-39]. This idea was promoted by the SONIC study [40], which showed an increased efficacy in achieving clinical outcomes with combined immunosuppression therapy. In this review, we found two studies with positive results and one study showing negative results for early combined therapy. However, a direct comparison in a clinical trial will be necessary if the guidelines are to be changed. Three RCTs looked into a direct comparison of the top-down and step-up protocols. Though the first two trials differed in population size, with Fan et al [18] evaluating fewer patients compared to D'Haens et al [17], their structure was similar, as both studies used CDAI score to assess patient remission and identical medication doses. The third, the REACT trial by Khanna et al [22], involved a large population in a multicenter study with patients enrolled from both Belgium and Canada. The HBI was used to determine remission.

Results from the studies by Fan et al [18] and D'Haens et al [17] seem to show a rapid initiation followed by a tapering effect with top-down therapy. D'Haens et al [17] found a significant difference in favor of patients in top-down in remission for the weeks $14,26,52$, and 104, but not 78 . These results appear to show a marked difference, especially at the earlier weeks of 14 and $26(\mathrm{P}=0.0001$ and $\mathrm{P}=0.006$, respectively). The difference was significant throughout the entire 104 week trial. However, one should note that the difference between patients in remission progression ranged from substantial to increasingly marginal. This suggests greater early efficacy in the achievement of remission for Crohn's patients in top-down therapy, but not a long-term benefit.

Likewise, Fan et al [18] demonstrated a significantly greater number of patients in remission at weeks 2, 6, 22, and 30 in the top-down therapy group. As in the study by D'Haens et al [17], there was a strong correlation between better remission rates 
and top-down therapy. Top-down therapy showed a rapid induction into remission, where $26.3 \%$ of top-down patients were in remission in week 2 compared to $2.6 \%$ of step-up patients, with week 2 and week 6 showing high significance $(\mathrm{P}=0.003$ and $\mathrm{P}=0.001$, respectively). As with the other study, the differences between top-down and step-up become insignificant in the later stages of treatment (week $54, \mathrm{P}=0.182$; week 102, $\mathrm{P}=0.209$ ).

However, results from the REACT trial showed that early combined immunotherapy had similar remission rates at 12 months in both top-down and step-up therapy groups: $66.0 \%$ of patients in the top-down cohort achieved remission compared with $61.9 \%$ of patients in the step-up cohort $(\mathrm{P}=0.5169)$. However, top-down therapy showed a reduction in the risk of surgery at 24 months $(\mathrm{P}=0.0003)$, surgeries $(\mathrm{P}=0.0314)$, and serious disease complications $(\mathrm{P}=0.0005)$. There was a notable difference between the Belgian patients and the Canadian patients in this study: Belgian patients were started on combined immunotherapy at 12 weeks from diagnosis while Canadian patients were initiated at 4 weeks.

From the first two studies, it may seem that combination therapy provides possible benefits compared to conventional step-up therapy in achieving remission quickly if started at week zero. This advantage over step-up could allow for better patient care, as time spent in remission is increased during the earlier portion of treatment. Comparatively, the 4-week or 12-week delay in the REACT trial [22] may have delayed the benefit of early combined therapy in achieving rapid remission.

Another aspect of early combined immunosuppression that needs to be assessed is safety. One major concern with combined therapy is the patients' susceptibility to developing adverse reactions due to the alteration of their normal immune function. Past studies have shown that immunomodulator use is associated with increased opportunistic infections [41] and that the addition of biologic therapy only exacerbates the risk [42]. However, adverse events did not increase in the top-down groups of either the D'Haens et al or Fan et al studies [17,18]. Moreover, in the REACT trial [22] the reduction in complications of Crohn's disease was shown to be superior in the top-down therapy group.

Despite their being well-controlled and well-designed trials, it is important to consider several weaknesses with respect to the studies analyzed here. The use of combined therapy makes it hard to discern whether biologics are the agents that primarily improve the patients' outcomes. The major role of immunomodulators in this setting may be related to the prevention of antibody formation against biologics. This makes it difficult to compare patients receiving azathioprine and infliximab $[17,18]$ with those using different combinations of biologics and immunomodulators [22]. Another weakness is the nature of the studies themselves, in which the flexible combined therapy allowed practitioners to change therapy during the trial. The open-label nature of the trials made it difficult to control factors in the treatment. Finally, the difference between the HBI and the CDAI as measures for remission may be a contributing factor in measuring the success of top-down therapy. Whether these are appropriate primary outcomes to measure-as opposed to the use of biomarkers of inflammation, such as fecal calprotectin and endoscopic mucosal healing, as well as other bowel damage indexes-remains to be demonstrated.

We believe that combined early immunosuppression shows merit as a viable treatment option. The precise efficacy of topdown therapy for improving remission rates has not been definitively shown in the long term. However, positive results have been found regarding combined top-down therapy reducing complications and surgical rates in the medium term.

In recent years, biologic therapy has entered the arsenal of treatments for Crohn's disease. This class of drugs is of greater potency in immunosuppression and has been suggested to be of greater efficacy. There were two studies with positive results and one study showing negative results for early biologic monotherapy. Three retrospective cohort studies looked at the effect of early biologic therapy. Both Kim et al [24] and Ghazi et al [23] determined that top-down patients did not respond better to early biologic therapy in retrospective cohort studies. In contrast, a recent study by Ma et al [34] found that early biologic therapy was beneficial.

The retrospective study by Ghazi et al [23] focused on remission rates associated with early biologic use. At all three time points -3 months, 6 months and 12 monthsremission rates among early users of biologics were not significant $(\mathrm{P}=0.59,0.69$, and 0.37 , respectively). In fact, the disease activity was higher in top-down patients at 12 months compared to step-up therapy. However, the baseline disease activity was higher in the biologic group. Furthermore, the study also showed that hospitalization rates were increased in the top-down therapy group $(\mathrm{P}=0.04)$. As it was a retrospective study, this suggests that there was a selection bias: patients with severe disease activity are more likely to go onto biologics. However, a positive sign to note is the faster decrease in disease activity in the early biologic group $(\mathrm{P}=0.01)$. Furthermore, the higher early response rates shown by Ghazi et al [23] and the increase in Short Inflammatory Bowel Disease Questionnaire quality of life scores may be suggestive of advantages provided by early biologic therapy.

In the study by Kim et al [24], operation rates were the primary outcome. When comparing top-down and stepup patients, no statistically significant difference was found with respect to operation rates $(\mathrm{P}=0.905)$. In addition, rates of reoperation did not differ significantly $(\mathrm{P}=0.418)$. These results seem to indicate that early biologic therapy does not provide any advantage in avoiding surgery. However, secondary outcomes may indicate otherwise. Disease duration was shown to be shorter in the top-down group compared to the step-up group $(\mathrm{P} \leq 0.001)$. It could be argued that time not spent in disease represents time in remission. With such a high level of significance, early biologic therapy may be effective at maintaining remission. Nevertheless, this may be associated with biologic use in general and not specifically early biologic use. Adverse effects were also inconclusive in this study. The rates of complications such as stricturing or penetrating Crohn's disease was lower in the top-down group $(\mathrm{P}=0.011)$, and rates of hospitalization were not increased $(\mathrm{P}=0.070)$.

However, positive results were shown in the study by $\mathrm{Ma}$ et al [34]. One primary outcome was occurrence of surgical 
resection. Early initiation of biologic therapy (combination of both infliximab and adalimumab) was associated with a reduction in the need for surgery $(\mathrm{P} \leq 0.001)$. The other primary outcome also showed improvements in the top-down group. The rate of secondary loss of response was lower in those in the top-down cohort $(\mathrm{P}=0.006)$. Both of these outcomes suggest that early biologic use had a positive effect on patient outcomes.

We believe that the various studies by Ghazi et al [23], Kim et al [24] and Ma et al [34] provide conflicting evidence regarding early biologic therapy. Weaknesses stem from the use of retrospective cohorts in the analysis. A possible weakness arising from the study designs is that the notion of a strict topdown therapy regimen probably did not exist for the earliest patients included in the study. Therefore, the accuracy of the results is limited, since the use and type of biologics were left to practitioner choice during this period. This may lead to variables that could not be controlled or were not recorded for analysis. These studies were performed in the era prior to the widespread use of drug monitoring, the biologic group might have done better had its treatment been maintained at therapeutic level.

For the Ma et al study, despite the authors aim to evaluate the merit of early biologic therapy, it is difficult to examine the benefits as they unfortunately failed to control for the concurrent use of immunomodulators. Thus, there is no current high-quality evidence to support an effective benefit with early biologic therapy alone. Ideally, the study should incorporate propensity score analysis to assess the severity of the disease severity.

One of the early interventions in the treatment of Crohn's disease is the use of immunomodulators. One study found positive results and two studies negative results for the effect of immunomodulatory therapy on remission rates. Four studies $[19,20,25]$ focused on remission as the primary endpoint to assess the efficacy of top-down therapy. In a systematic review, immunomodulators were not shown to be effective in inducing remission in active Crohn's patients [43]. In a small clinical pediatric trial, however, the addition of 6-mercaptopurine to a steroid regimen was shown to significantly reduce the need for steroid use and to improve remission rate [21].

Two recent RCTs $[19,20]$ assessing the value of early immunomodulators show apparently undesirable results. The study conducted by Panés et al [19] determined that, at the primary endpoint of 76 weeks, the difference between the remission rates of the top-down and step-up groups was insignificant $(\mathrm{P}=0.47)$. The difference was also not significant at earlier follow-up points of 28 and 50 weeks $(\mathrm{P}=0.86$ and $\mathrm{P}=0.99$ ). However, patients in the top-down group suffered fewer relapses compared to the step-up group (11.8\%; 95\% confidence interval [CI], 5.2-21.8\%). Based on an intention-totreat analysis, the $20.6 \%$ drop-out rate in the top-down group would have a major statistical effect on the results. Nevertheless, the overall results from this study seem to show no advantage for azathioprine in inducing remission.

Likewise, the study by Cosnes et al [20] found that the rate of patients in remission was only higher in the early trimesters $(\mathrm{P}=0.036)$ before becoming similar. As in the study by Panés et al [19], this trial also suffered a large attrition of patients due to intolerances to azathioprine treatment. Seventeen patients were lost from the early immunomodulatory group and four were lost from the control group. With such a large attrition rate, only 41 top-down and 40 step-up patients completed the three-year trial. Notably, one patient required discontinuation of the immunomodulator because of neutropenia. While the large loss of patients from this study limits the interpretation of its results, it does suggest an increased risk of adverse events during immunomodulatory treatment.

Thesetwo RCTs $[19,20]$ suggest thatearlyimmunomodulators may provide little benefit, along with an increased risk of adverse effects. In contrast, the retrospective study by Kwak et al [25] found that early use of immunomodulatory therapy was superior to step-up therapy in inducing clinical remission and corticosteroid free remission $(\mathrm{P}=0.043$ and $\mathrm{P}=0.035)$. The secondary outcome of relapse was also investigated, but relapse rates were shown to be not statistically different $(\mathrm{P}=0.827)$. One major finding was that early azathioprine use was associated with a significant increase in adverse events $(\mathrm{P}=0.029)$, further supporting the possibility that early immunomodulator use is associated with more complications.

We believe that despite attempts to perform highquality studies to monitor patients' exposure to early immunomodulators, these studies show a high attrition rate. Both RCTs suggested little benefit from top-down immunomodulatory therapy, raising doubts about the efficacy of early immunomodulatory therapy in achieving remission. This is only countered by benefits in reducing the time to steroid-free remission [25], reduction in perianal surgery [20] and prevention of relapse [19]. It is also questionable whether the risk posed by the early introduction of immunomodulators is worth the improvement in symptoms. The associated increased risk of developing adverse effects demands greater measures to ensure patient safety. For improving remission rates, the clinician must weigh the risk and benefit of early immunomodulatory therapy prior to its administration.

The incidence of surgery is another method of assessing the effectiveness of medical therapy. In this regard, there were only three studies with positive results and one study showing negative results for the effect of early immunomodulatory therapy on improving surgery rates. Surgery is considered the last line and the most extreme intervention to be applied in Crohn's patients. A reduction in rates of surgery can be used as an outcome for the success of a treatment regime. Since immunomodulator use has been implemented for many years, early immunomodulator use was investigated for improvements in the long-term outcome of surgical rates. Four retrospective cohort studies [26-29] were conducted using information from comprehensive data bases.

In a subanalysis of 879 patients out of 5640 patients, Chatu et al [26] found no advantage of early immunomodulator use within one year of diagnosis. Surgery rates between the groups was shown to be not significant as confidence intervals overlapped (hazard ratio [HR] $0.41 ; 95 \%$ CI $0.27-0.61$ vs. HR 0.21 ; 95\%CI 0.13-0.34).

Conversely, Ramadas et al [27], in a study of 341 patients, found that the HR for surgery in the 129 early 
immunomodulator patients was lower. Immunomodulator use within one year of diagnosis had a strong correlation with better surgery rates $(\mathrm{P}=0.001)$. Likewise, Kariyawasam et al [28] found that 189 of 1035 patients who received early immunomodulatory therapy within three years of diagnosis had significantly lower surgical rates $(\mathrm{P} \leq 0.001)$. Lakatos et al [29] found comparable results in 123 patients $(\mathrm{P}=0.001)$. Furthermore, this group found that 70 patients who received "very early" immunomodulatory therapy had a significantly smaller need for surgery ( $\mathrm{P}=0.023)$.

The results of these studies seem to suggest that a reduction in the rate of surgery may be possible with early immunomodulator use. Whether or not this is an independent factor may be difficult to discern, given the retrospective nature of the studies. Furthermore, in all these studies, the definition of top-down therapy was relatively late (within one to three years of diagnosis). With such a large timeframe to define top-down therapy, the use of other induction methods, such as corticosteroids from step-up therapy, may have been included. In addition, Lakatos et al [29] found that the use of azathioprine in the first year of treatment increased from rates as low as $11.4 \%$ in $1989-1999$ to $34.2 \%$ in $1999-2008$. Therefore, given the large range of time interval defined as "early" treatment, the use of early therapy may not in fact be the variable resulting in better outcomes; instead, it may simply be the use of azathioprine itself.

We believe that these results imply that the use of immunomodulators can alter the natural course of Crohn's disease towards reducing surgery. As surgical rates can only be collected through long-term data, the continued use of azathioprine should be monitored to confirm the improvements in surgical rates achieved by early immunomodulator use.

Pediatric patients are of interest as they differ from adult patients in genetic profile and disease presentation [44]. First of all, the six pediatric studies assessed here were comparable since they all used the PCDAI score. However, there was a lack of large studies comparing each of the three treatment paradigms: early combined immunosuppression, early biologic, and early immunomodulatory therapy. The definition of top-down therapy was also similar, with three papers defining it as starting within three months [21,33,35] and another three [30-32] at week zero.

The similarity of the populations in the studies of Punati et al [33] and Walters et al [35] is of interest: they both had an average age around 11 years old, a proportion of male patients around $60 \%$, and assessment using the PCDAI scale. The difference is that Punati et al [33] used early immunomodulatory treatment only, while Walters et al [35] had groups using early biologic therapy, early immunomodulatory therapy and stepup therapy. This provided a unique opportunity to compare all three therapy types.

Punati et al [33] found that the rates of remission in the top-down cohort were not different from the rates of remission in the conventional step-up group. At the time points of 12,18 , and 24 months, rates of remission were $60 \%$ versus $56 \%, 67 \%$ versus $61 \%$, and $72 \%$ versus $72 \%$ respectively. Surgery rates were also not significant at any time point. Hospitalization rates were not found to be different in the first year, but were lower in the top-down group compared to the step-up group $(\mathrm{P}=0.03)$ in the second year. Moreover, corticosteroid use was significantly less common in the top-down group early in treatment $(\mathrm{P}=0.005)$.

Conversely, the recent results of the larger trial by Walters et al [35] point to a greater efficacy of top-down therapy in achieving remission with the use of early immunomodulatory therapy. At the time point of one year, the percentage of patients in remission in the early biologic group was $85.3 \%$, compared to $60.3 \%$ and $54.4 \%$ in the early immunomodulator and step-up groups, respectively. The difference between the early biologics and the other two regimens was significant (immunomodulatory, $\mathrm{P}=0.017$; step-up, $\mathrm{P}=0.0002$ ). Early immunomodulatory therapy was not significant when compared to step-up therapy $(\mathrm{P}=0.49)$. What these results imply is a significant superiority of early biologic therapy over both early immunomodulatory therapy and step-up therapy. A benefit for early immunomodulatory therapy was not shown.

The remaining three other studies [30-32] investigating top-down therapy in pediatric Crohn's disease were cohort studies. The study by Lee et al [31] included 36 patients in three cohorts: early immunosuppression combined with infliximab, early immunomodulator and step-up therapy. Results from the study showed lower relapse rates within the combined immunosuppression group compared to the other two treatment groups. This was significant compared to the other two groups at both one and two years $(\mathrm{P}=0.012$ and $\mathrm{P}=0.029$ ). Interestingly, the use of immunomodulators only was significantly more effective compared to step-up therapy at both time points ( $\mathrm{P}=0.047$ for both).

A different study by Lee et al [30] investigated the efficacy of early biologic therapy versus step-up therapy in 28 patients. The authors concluded that the top-down regimen was not more effective than the step-up therapy in stopping relapse at one year $(\mathrm{P}=0.091)$; the difference was significant at the twoyear follow-up point $(\mathrm{P}=0.048)$, but not the last follow-up point at three years $(\mathrm{P}=0.194)$.

Finally, a study by Olbjørn et al [32] compared early biologic against step-up therapy in 36 patients. While early biologic therapy was significantly more effective as regards remission rates $(\mathrm{P}=0.03)$, this treatment was associated with upper gastrointestinal lesions $(\mathrm{P}=0.03)$. Furthermore, the reduction in disease activity was shown to be not significant $(\mathrm{P}=0.4)$.

The results from these studies show different data for top-down therapy. However, these trials were conducted with relatively small patient populations which, despite normalization, could potentially be influenced by extreme cases. Furthermore, since two of these studies were conducted in Korea, it may be difficult to compare these studies to other patient populations, given the possible differences between western and East Asian populations [36]. Therefore, any conclusions drawn from these studies [30-32] should be treated with caution.

We believe that overall, there appears to be disagreement as to whether top-down therapy provides a benefit over step-up therapy in achieving clinical outcomes in pediatric patients. Furthermore, the lack of more rigorously conducted studies, using objective biomarkers and assessment of mucosal healing, 
makes it difficult to identify the efficacy of the three treatment paradigms. While there are differences in Crohn's disease in pediatric patients, this may be an extension of the evidence showing inconclusive results for top-down therapy in affecting the natural course of Crohn's diseases in the pediatric population.

Even though this appraisal may be of some merit in providing insights into the evidence of top-down treatment regimens, it has its own limitations. Firstly, the lack of standardization between studies creates a challenge when one attempts to compare results. The differences in medication type, dosage, combination and timing were all variable. Therefore, only a limited comparison of the studies can be made as regards the broad concept of top-down therapy.

For instance, the variety of treatment regimens used by different health centers (early combined immunosuppression, early biologic, and early immunomodulatory therapy), as well as differences in endpoints for assessing treatment efficacy (inducing remission or reduction in surgical rates), limit the value of any comparisons. Other factors, such as the clinical heterogeneity of early- and late-onset disease (pediatric versus adult), may also have affected the responses to treatment. Furthermore, the time from diagnosis to the use of top-down treatment is not universally constant. Centers considered several different timeframes as "early".

The central theme of the top-down therapy used by the medical community was the introduction of high-level immunosuppressive drugs early in treatment, in place of a gradual increase starting from the bottom of the therapeutic pyramid. This dilemma has been described as Crohn's patients being "presumed innocent or presumed guilty" at diagnosis [45]. In other words, clinicians using top-down therapy are essentially treating all their patients as if they have severe disease (guilty), while clinicians using step-up therapy are managing all their patients as if they have only mild disease (innocent). Aggressive therapy like the top-down approach should theoretically benefit those who have severe disease, while a less aggressive approach, such as step-up therapy, will better suit those with a milder presentation. Consequently, top-down therapy using aggressive high levels of early immunosuppression as first-line treatment for all patients creates the risk of over-treating patients with mild disease.

There was a marked difference among the studies with respect to the definition of "aggressive treatment". Thus, articles were appraised and evaluated based on the types of medication used early in treatment. Since many of the studies assessed the efficacy of immunomodulators and biologics, this evaluation addressed the effect of immunomodulators and biologics in terms of different endpoints: "remission" and "surgery."

This review is by nature a critical appraisal. Therefore, a direct and objective analysis of the data is not possible. In this study, we selected SIGN as a widely used critical appraisal with the advantage of being simple to use [46]. Comparisons between data sets were based on assessment from appraisal and will inevitably be at risk of author bias. If a meta-analysis was completed, data would be subject to a method of comparison with less risk of bias.

Crohn's disease itself presents as a complex collection of chronic symptoms. Therefore, variation in the treatment of patients and their response to treatments is unavoidable. Furthermore, newer medications have been released in the short time span during which top-down therapy has been practiced. Variability in different institutions' access to these medications, for economic and budgetary reasons, affects the ability to conduct well-designed studies in different populations.

A final weakness is the variation in the patient groups' ethnicities. Among different populations the baseline features of Crohn's disease will inevitably vary. The geographic and ethnic nature of some of the studies included here, as well as genetic differences among populations, mean that the findings may be viewed in regional, rather than global, terms. In addition, most reported studies mainly focused on clinical remission but lacked consistent reporting of objective findings, such as mucosal healing or bowel damage, when comparing both approaches. Ideally, endoscopic, transmural healing and/ or biochemical definitive endpoints should be considered for future trials investigating the clinical outcomes of step-up versus top-down [47].

Although it is beyond the scope of the objectives and goals of this review article, it is important to point out that a team of scientists recently reported that they had identified a set of genetic markers that determine the severity of Crohn's disease [48]. Such a molecular biomarker has also been found to be potentially useful for predicting outcomes for individual Crohn's patients [48]. The implication of this finding is extremely important, as the prognosis in Crohn's disease could come from and be governed by separate genetic loci. By understanding the genes that may be involved in determining the outcomes in Crohn's patients, one could develop therapies that would involve targeted biologic pathways. Moreover, one could also stratify patients and develop new personalized therapies based on their genetic involvement $[48,49]$.

\section{Concluding remarks and future implications}

Results from the 19 clinical trials showed both benefits and disadvantages in the application of top-down therapy. Combined immunosuppression showed possible positive results in achieving remission if administered from week 0. Furthermore, while remission benefits were not shown in the large REACT trial [22], a reduction in complications was appreciated. On the other hand, early biologic treatment did not have a clear benefit over step-up therapy, but the analysis of this result was limited by the number and types of studies. The argument for early immunomodulatory therapy is also unclear; while surgery rates were seemingly improved by early administration, it was difficult to attribute the benefit to the early therapy because of the long time intervals used to define top-down regimens. Remission was easier to assess, but again early immunomodulatory therapy did not appear to be more effective than step-up therapy, even though a steroid sparing effect and a lower number of relapses were seen in the early immunomodulatory group. In pediatric patients, clinical outcomes in larger studies appeared to show a positive effect, 
whereas smaller studies failed to find a strong case for topdown therapy. The number and types of studies carried out in pediatric populations presented an obstacle to reviewing the efficacy of top-down therapy.

Crohn's disease remains a challenge for practitioners to treat, and top-down therapy will be a continued area of research in the coming years. As advances are made in the field of monoclonal antibodies, the development of newer biologic immunosuppressing drugs will continue. However, given the costs and potential side-effects of the long-term use of immunosuppression, care should be taken in designing trials to ensure that well-designed treatment regimens with appropriate disease stratification and objective outcome measures can provide good evidence for future treatment.

In its current state, nevertheless, the mainstay of therapy continues to be based largely on imprecise treatment using either "step-up" or newly proposed "top-down" approaches. Research and evidence supporting top-down therapy remain limited. Combined therapy showed promising results over both early biologic and early immunomodulatory treatment and may be a recommended area for further study. Drug combinations, timing, and dosage are all areas that should be addressed. Considering this, we recommend that the most desirable treatment for a newly diagnosed Crohn's disease patient should be a personalized and tailored approach and that the disease should be stratified for each patient, taking into consideration the location, extent, previous disease course and severity of their Crohn's disease, as well as their comorbidities and the patient's personal preferences. Combined ("top-down") therapy should be considered for patients with complicated disease,with poor prognostic factors (e.g. diagnosis as pediatric patient, recurrent flare-up, steroid dependent, multiple failed steroid treatments), and extensive disease suggestive of an aggressive disease course (e.g. perianal disease, evidence of severe bowel damage and/ or need for surgical intervention). Patients undergoing topdown therapy must be place under close monitoring to ensure their safety prior to their intensive treatment [8]. Further research will need to focus on investigation into the genetics and pathophysiology of Crohn's disease. Only with proper understanding of the nature of Crohn's disease can one truly develop precision therapy that targets relevant pathologic pathways. If precise medications can be identified to achieve specific outcomes, a more personalized and targeted treatment may be possible $[48,49]$.

\section{References}

1. Baumgart DC. The diagnosis and treatment of Crohn's disease and ulcerative colitis. Dtsch Arztebl Int 2009;106:123-133.

2. Derwa Y, Williams CJM, Sood R, et al. Factors affecting clinical decision-making in inflammatory bowel disease and the role of point-of-care calprotectin. Therap Adv Gastroenterol 2018;11:1-18.

3. Rutgeerts P, Geboes K, Vantrappen G, Beyls J, Kerremans R, Hiele M. Predictability of the postoperative course of Crohn's disease. Gastroenterology 1990;99:956-963.

4. Lichtenstein GR, Hanauer SB, Sandborn WJ; Practice Parameters Committee of American College of Gastroenterology.
Management of Crohn's disease in adults. Am J Gastroenterol 2009; 104:465-483, 484.

5. Travis SP, Stange EF, Lémann M, et al. European Crohn's and Colitis Organisation. European evidence based consensus on the diagnosis and management of Crohn's disease: current management. Gut 2006;55 Suppl 1:i16-i35.

6. Mowat C, Cole A, Windsor A, et al. IBD Section of the British Society of Gastroenterology. Guidelines for the management of inflammatory bowel disease in adults. Gut 2011;60:571-607.

7. NICE. Crohn's disease: NICE guidelines. NICE; 2012.

8. Amezaga AJ, Van Assche G. Practical Approaches to "top-down" therapies for Crohn's disease. Curr Gastroenterol Rep 2016;18:35.

9. Rogler G. Top-down or step-up treatment in Crohn's disease? Dig Dis 2013;31:83-90.

10. Binion DG. Biologic therapies for Crohn's disease: Update from the 2009 ACG Meeting. Gastroenterol Hepatol (N Y) 2010;6:4-16.

11. Paulson EC. Biologic therapy and surgery for crohn disease. Clin Colon Rectal Surg 2013;26:128-134.

12. Hanauer SB, Feagan BG, Lichtenstein GR, et al. ACCENT I Study Group. Maintenance infliximab for Crohn's disease: the ACCENT I randomised trial. Lancet 2002;359:1541-1549.

13. Hanauer SB, Sandborn WJ, Rutgeerts P, et al. Human anti-tumor necrosis factor monoclonal antibody (adalimumab) in Crohn's disease: the CLASSIC-I trial. Gastroenterology 2006;130:323-333.

14. Sandborn WJ, Rutgeerts P, Enns R, et al. Adalimumab induction therapy for Crohn disease previously treated with infliximab: a randomized trial. Ann Intern Med 2007;146:829-838.

15. Schreiber S, Khaliq-Kareemi M, Lawrance IC, et al. PRECISE 2 Study Investigators. Maintenance therapy with certolizumab pegol for Crohn's disease. N Engl J Med 2007;357:239-250.

16. Feagan BG, Sandborn WJ, Gasink C, et al. Ustekinumab as Induction and Maintenance Therapy for Crohn's Disease. N Engl J Med 2016;375:1946-1960.

17. D’Haens G, Baert F, van Assche G, et al. North-Holland Gut Club. Early combined immunosuppression or conventional management in patients with newly diagnosed Crohn's disease: an open randomised trial. Lancet 2008;371:660-667.

18. Fan R, Zhong J, Wang ZT, Li SY, Zhou J, Tang YH. Evaluation of "top-down" treatment of early Crohn's disease by double balloon enteroscopy. World J Gastroenterol 2014;20:14479-14487.

19. Panés J, López-Sanromán A, Bermejo F, et al. AZTEC Study Group. Early azathioprine therapy is no more effective than placebo for newly diagnosed Crohn's disease. Gastroenterology 2013;145:766-774.e1.

20. Cosnes J, Bourrier A, Laharie D, et al. Groupe d'Etude Thérapeutique des Affections Inflammatoires du Tube Digestif (GETAID). Early administration of azathioprine vs conventional management of Crohn's Disease: a randomized controlled trial. Gastroenterology 2013;145:758-765.e2.

21. Markowitz J, Grancher K, Kohn N, Lesser M, Daum F. A multicenter trial of 6-mercaptopurine and prednisone in children with newly diagnosed Crohn's disease. Gastroenterology 2000;119:895-902.

22. Khanna R, Bressler B, Levesque BG, et al. Early combined immunosuppression for the management of Crohn's disease (REACT): a cluster randomised controlled trial. Lancet 2015;386:1825-1834.

23. Ghazi LJ, Patil SA, Rustgi A, Flasar MH, Razeghi S, Cross RK. Step up versus early biologic therapy for Crohn's disease in clinical practice. Inflamm Bowel Dis 2013;19:1397-1403.

24. Kim NH, Jung YS, Moon CM, et al. Long-term clinical outcomes of korean patient with Crohn's disease following early use of infliximab. Intest Res 2014;12:281-286.

25. Kwak MS, Kim DH, Park SJ, et al. Efficacy of early immunomodulator therapy on the outcomes of Crohn's disease. BMC Gastroenterol 2014;14:85. 
26. Chatu S, Saxena S, Subramanian V, et al. The impact of timing and duration of thiopurine treatment on first intestinal resection in Crohn's disease: national UK population-based study 1989-2010. Am J Gastroenterol 2014;109:409-416.

27. Ramadas AV, Gunesh S, Thomas GA, Williams GT, Hawthorne AB. Natural history of Crohn's disease in a population-based cohort from Cardiff (1986-2003): a study of changes in medical treatment and surgical resection rates. Gut 2010;59:1200-1206.

28. Kariyawasam VC, Selinger CP, Katelaris PH, et al. Early use of thiopurines or methotrexate reduces major abdominal and perianal surgery in Crohn's disease. Inflamm Bowel Dis 2014;20:1382-1390.

29. Lakatos PL, Golovics PA, David G, et al. Has there been a change in the natural history of Crohn's disease? Surgical rates and medical management in a population-based inception cohort from Western Hungary between 1977-2009. Am J Gastroenterol 2012;107:579-588.

30. Lee YS, Baek SH, Kim MJ, Lee YM, Lee Y, Choe YH. Efficacy of early infliximab treatment for pediatric Crohn's disease: a three-year follow-up. Pediatr Gastroenterol Hepatol Nutr 2012;15:243-249.

31. Lee JS, Lee JH, Lee JH, et al. Efficacy of early treatment with infliximab in pediatric Crohn's disease. World J Gastroenterol 2010;16:1776-1781.

32. Olbjørn C, Nakstad B, Småstuen MC, Thiis-Evensen E, Vatn MH, Perminow G. Early anti-TNF treatment in pediatric Crohn's disease. Predictors of clinical outcome in a population-based cohort of newly diagnosed patients. Scand J Gastroenterol 2014;49:1425-1431.

33. Punati J, Markowitz J, Lerer T, et al. Pediatric IBD Collaborative Research Group. Effect of early immunomodulator use in moderate to severe pediatric Crohn disease. Inflamm Bowel Dis 2008;14:949-954.

34. Ma C, Beilman CL, Huang VW, et al. Anti-TNF therapy within 2 years of Crohn's disease diagnosis improves patient outcomes. Inflamm Bowel Dis 2016;22:870-879.

35. Walters TD, Kim MO, Denson LA, et al. PRO-KIIDS Research Group. Increased effectiveness of early therapy with anti-tumor necrosis factor- $\alpha$ vs an immunomodulator in children with Crohn's disease. Gastroenterology 2014;146:383-391.

36. Kim ES, Kim WH. Inflammatory bowel disease in Korea: epidemiological, genomic, clinical, and therapeutic characteristics. Gut Liver 2010;4:1-14.

37. Colombel JF, Sandborn WJ, Rutgeerts P, et al. Adalimumab for maintenance of clinical response and remission in patients with Crohn's disease: the CHARM trial. Gastroenterology 2007;132:52-65.

38. Ford AC, Sandborn WJ, Khan KJ, Hanauer SB, Talley NJ, Moayyedi P. Efficacy of biological therapies in inflammatory bowel disease: systematic review and meta-analysis. Am J Gastroenterol 2011;106:644-659, quiz 660.

39. Peyrin-Biroulet L, Deltenre P, de Suray N, Branche J, Sandborn WJ, Colombel JF. Efficacy and safety of tumor necrosis factor antagonists in Crohn's disease: meta-analysis of placebo-controlled trials. Clin Gastroenterol Hepatol 2008;6:644-653.

40. Colombel JF, Sandborn WJ, Reinisch W, et al. Infliximab, azathioprine, or combination therapy for Crohn's disease. $N$ Engl J Med 2010;362:1383-1395.

41. Lichtenstein GR, Feagan BG, Cohen RD, et al. Serious infections and mortality in association with therapies for Crohn's disease: TREAT registry. Clin Gastroenterol Hepatol 2006;4:621-630.

42. Colombel JF, Loftus EV Jr, Tremaine WJ, et al. The safety profile of infliximab in patients with Crohn's disease: the Mayo clinic experience in 500 patients. Gastroenterology 2004;126:19-31.

43. Chande N, Tsoulis DJ, MacDonald JK. Azathioprine or 6-mercaptopurine for induction of remission in Crohns disease. Cochrane Database Syst Rev 2013;(4):CD000545.

44. de Ridder L, Weersma RK, Dijkstra G, et al. Genetic susceptibility has a more important role in pediatric-onset Crohn's disease than in adult-onset Crohn's disease. Inflamm Bowel Dis 2007;13:1083-1092.

45. Hanauer SB. Top-down versus step-up approaches to chronic inflammatory bowel disease: presumed innocent or presumed guilty. Nat Clin Pract Gastroenterol Hepatol 2005;2:493.

46. Baker A, Young K, Potter J, Madan I. A review of grading systems for evidence-based guidelines produced by medical specialties. Clin Med (Lond) 2010;10:358-363.

47. Koutroumpakis E, Katsanos KH. Implementation of the simple endoscopic activity score in crohn's disease. Saudi J Gastroenterol 2016;22:183-191.

48. Lee J, Biasci D, Noor N, et al. OC-044 Profile trial: predicting outcomes for Crohn's disease using a molecular biomarker. Gut 2017;66:A22-A23.

49. Lee JC, Biasci D, Roberts R, et al. Genome-wide association study identifies distinct genetic contributions to prognosis and susceptibility in Crohn's disease. Nat Genet 2017;49:262-268.

50. Aloi M, Nuti F, Stronati L, Cucchiara S. Advances in the medical management of paediatric IBD. Nat Rev Gastroenterol Hepatol 2014;11:99-108.

\section{Appendix}

Critical Appraisal Skills Programme

Link: http://www.casp-uk.net/casp-tools-checklists

\section{Bias checklist}

\begin{tabular}{l}
\hline Type of bias \\
\hline Random sequence generation \\
Allocation concealment \\
Blinding of participants and personnel \\
Blinding of outcome assessment \\
Incomplete outcome data \\
Selection reporting \\
Other bias
\end{tabular}

